\title{
Optimal Wavelet Selection for the Size Estimation of Manufacturing Defects of Tapered Roller Bearings with Vibration Measurement using Shannon Entropy Criteria
}

\author{
Krisztián Deák* - Tamás Mankovits - Imre Kocsis \\ University of Debrecen, Faculty of Engineering, Hungary
}

Fault diagnosis of bearings is essential in manufacturing to increase quality. Traditionally, fault diagnosis of tapered roller element bearings is performed by signal processing methods, which handle the nonstationary behaviour of the signal. The wavelet transform is an efficient tool for analysing the vibration signal of the bearings because it can detect the sudden changes and transient impulses in the signal caused by faults in the bearing elements. In this article, manufacturing faults on the outer ring of tapered roller bearings due to the grinding process in manufacturing are investigated. Nine different real values wavelets (Symlet-2, Symlet-5, Symlet-8, db02, db06, db10, db14, Meyer, and Morlet) are compared according to the Energy-to-Shannon-Entropy ratio criteria, and which is efficient for detecting the manufacturing faults is determined. Finally, experiments are carried out on a test rig for determining the geometrical size of the manufacturing faults with all wavelets directly from the vibration signature the result of db02, Symlet-5, and Morlet wavelets are presented. When modelling the bearing structure as an under-damped second-order mass-spring-damper mechanical system, its unit impulse response function is compared to the wavelets on the basis of their Energy-to-Shannon-Entropy ratio to determine the fault size from the vibration signal. The proposed technique has been successfully implemented for measuring defect widths. The maximum deviation in result has been found to be $4.12 \%$ for the defect width which was verified with image analysis methods using an optical microscope and contact measurement.

Keywords: condition monitoring, bearing vibration analysis, wavelet, entropy, dynamic model

Highlights

- A new method for diagnosis of manufacturing faults of tapered roller bearings has been developed.

- The geometrical size of the fault has been calculated from the vibration signature.

- $\quad$ Nine different wavelets have been compared as regards to their efficiency for fault diagnosis on the basis of Energy-toShannon-Entropy ratio criteria to reveal the faults.

- A sensitive and accurate test rig has been developed with high-quality data acquisition system to obtain precise measurement data.

- Verification using an optical microscope and contact measurement showed a slight deviation from the measured values; the method could be applied in industrial applications.

\section{O INTRODUCTION}

Production of tapered roller bearings is a sophisticated process influenced by several factors, such as worn table traverse mechanisms, inappropriate technological parameters, incorrect grinding wheels, vibrations due to the spindle mechanism, or dirty coolant. Investigation of the effects of the different manufacturing faults to the vibration generated is still an important and demanding task.

Research on various bearing defects by vibration analysis mostly focus on operational defects caused by wear and cracks. Patel et al. [1] used envelope methods to reveal local faults on the races of deep groove ball bearings. Kalman and $\mathrm{H}$ filters were applied by Khanam et al. [2] to measure bearing faults, especially in noisy condition with low signalto-noise ratios when it was difficult to identify the useful components of the vibration signal. Acoustic emission measurement is a powerful method to detect cracks inside the bearing material, which are the initial reasons of fatigue spallings. Al-Ghamd and $\mathrm{Mba}$ [3] applied this method combined with the traditional vibration analysis to determine the bearing outer race defect width directly from the raw signal. Elforjani and Mba [4] emphasized the effectiveness of acoustic emission methods in the case of slowspeed bearings. Sawalhi and Randall [5] execute their research to determine the fault size of the bearings from the vibration signal by analysing the entry and exit impulses.

Because of their flexibility and computational efficiency, wavelets are perfect tools for fault feature extraction, singularity detection for signals, denoising, and extraction of the weak signals from the vibration signals. These applications were presented by Peng and Chu [6]. Discrete wavelet transform with Daubechies-4 (db04) mother wavelets to analyse the combination of different faults on the races of ball bearings were used by Prabhakar et al. [7]. The 
combination of envelope spectrum and wavelet transform for the extraction of defect problems in bearings were used by Shi et al. [8].

Nikolaou and Antoniadis [9] applied complex shifted Morlet wavelets to analyse vibration signals generated by rolling element bearings.

Qiu et al. [10] successfully used a wavelet filter-based weak signature detection method and its application for diagnosis of rolling element bearings.

Junsheng et al. [11] pointed out the effectiveness of impulse response wavelet to the fault diagnosis of rolling element bearings.

Symlet wavelets were used efficiently in the study of Kumar and Singh [12]. In their study, tapered roller bearings were analysed to determine the fault size on the outer ring.

Symlet wavelet is an effective tool for noise reduction in ECG signals because it can filter out the useful components of the complex signal from the noisy background [13]. Symlet-5 wavelet represents the entry and impact events as the roller hits the defects during operation of the bearing. A detailed study was presented about the decomposition of the vibration signals using discrete wavelet transform with Symlet- 5 by Kumar et al. [14].

Analytical Wavelet Transform-(AWT) based acoustic emission techniques for identifying the inner race of the radial ball bearing were applied by Kumar et al. [15].

Yan and Gao [16] revealed localized structural defects and conducted experiments in their studies using multi-scale enveloping spectrogram for the vibration analysis of bearings.

Patil et al. [17] developed an analytical model and simulation to predict the effect of a localized defect on the ball bearing vibrations by considering the contact between the ball and the races as non-linear springs.

Optimal wavelet filtering and sparse code shrinkage were presented by He et al. [18]. To extract the impulsive features buried in the vibration signal, a hybrid method which combines a Morlet wavelet filter and sparse code shrinkage (SCS) was proposed. First, the wavelet filter was optimized using differential evolution (DE) to eliminate the interferential vibrations and obtain the fault characteristic signal. Then, to further enhance the impulsive features and suppress residual noise, SCS, which was a softthresholding method based on maximum likelihood estimation (MLE), was applied to the filtered signal.

Simulations and signal processing techniques to track the spall size were used by Sawalhi and Randall [19].
Kumar and Singh [20] applied the discrete wavelet transform of the vibration signal to determine the outer race defect width measurement in tapered roller bearings, which was previously prepared using an electric discharging machine.

Khanam et al. [21] estimated the fault size in the outer race of ball bearings using the discrete wavelet transform of the vibration signal.

Tóth and Tóth [22] and [23] revealed artificial faults of the inner rings of deep groove bearings by wavelet analysis. A realistic signal model of ball bearings with inner race fault was created to design a new wavelet to reveal the defect more efficiently from the vibration signature.

Beyond vibration analysis, there are other diagnosis methods, e.g. oil analysis, which could enhance the efficiency of methods [24].

Zhuang $\mathrm{Li}$ et al. applied wavelet transform with an artificial neural network for the diagnosis of gearboxes [25].

Machine-learning methods for the optimization of parameters such as support vector machines were used by Mankovits et al. [26].

Khanam et al. [27] presented a theoretical model for the force function as a bearing rolling element hits a spall-like defect on the inner race. The vibratory response was simulated with a fourth-order Runge Kutta method and analysed in both time and frequency domain. It offers a platform for monitoring the size defect.

Borghesani et al. [28] applied cepstrum prewhitening for diagnostics of rolling element bearings. Due to its moderate computational requirements, it was an appropriate tool for an automatic damage recognition algorithm. A comparison with the traditional pre-whitening techniques revealed that cepstrum pre-whitening was a more suitable and efficient tool for automatic fault detection.

Figlus and Stanczyk [29] presented a method of diagnosing damage to rolling bearings near toothed gears of processing lines. Vibration response was measured with a laser vibrometer. Discrete wavelet transform was successfully applied to detect damage.

Tabaszewski [30] researched the classification of defects of rolling bearings by k-NN classifier with regard to the proper selection of the observation place. Typical parameters, such as root mean square (r.m.s) and peak values of the vibration signal and the energy of acoustic emission pulses was found to be effective for revealing cracks in the outer rings.

Gligorijevic et al. [31] presented an automated technique for the early fault detection of rolling element bearings by dividing the signal to sub- 
bands by means of wavelet decomposition. A twodimensional feature space was used for fault detection of the bearing elements by quadratic classifiers with high accuracy.

Strączkiewicz et al. [32] applied supervised and unsupervised pattern recognition methods for damage classification and the clustering of rolling bearings. Clustering analysis was effective for determining the number of bearing state conditions.

Slavič et al. [33] used force measurement instead of the traditional acceleration measurement to identify bearing faults. The signal was processed using an envelope technique. The research showed that frequency domain analysis could successfully be applied to identify both amplitude and frequency of the force signal. The procedure was also applied to a high-series production line.

Abboud et al. [34] characterized bearing fault vibrations and explored angle/time cyclo-stationary properties. They experimentally validated their results on real vibration signals and the possible application for bearing fault detection.

Paya et al. [35] analysed drive lines with multiple faults that consist of an automotive gearbox, disc brake, and bearings. The paper presented an investigation to study both bearing and gear faults by wavelet transform then classified by multilayer backpropagation artificial neural networks to classify the faults into groups.

Antoni [36] applied a cyclic spectral tool for the incipient fault diagnosis of rolling element bearings. They demonstrated the optimality of cyclic coherence. It was proved that the diagnostic information is perfectly preserved in the cyclic frequency domain as a symptomatic pattern of spectral lines.

\section{FEATURE EXTRACTION FROM THE VIBRATION SIGNAL}

\subsection{Optimal Wavelet Selection}

The wavelet transform is continuous or discrete, and it is calculated by the convolution of the signal and a wavelet function. A wavelet function is a small oscillatory wave, which contains both the analysis and the window function. Continuous wavelet transform (CWT) generates the two-dimensional maps of coefficients that are called scalograms:

$$
C W T_{f}(a, b)=\frac{1}{\sqrt{a}} \int_{-\infty}^{\infty} f(t) \cdot \psi^{*}\left(\frac{t-b}{a}\right) d t,
$$

where $a$ is the scale parameter, $b$ is the translation parameter, $f(t)$ is the signal in time domain, $\psi$ is the 'mother' wavelet, and $\psi^{*}$ is the complex conjugate of $\psi[37]$.

The benefit of CWT is that by changing the scale parameter, the duration and bandwidth of wavelet are both changed, providing better time or frequency resolution, but its shape remains the same. The scale parameter can be continuous or dyadic. The CWT uses short windows at high frequencies and long windows at low frequencies.

The scalogram, defined as the squared magnitude of CWT, always has non-negative, real-valued timefrequency (scale) distribution. Its resolution in the time-frequency plane depends on the scale parameter.

$$
\begin{aligned}
& S C\{f(a, b)\}=\left|C W T_{f}(a, b)\right|^{2}= \\
& =\left|\int_{-\infty}^{\infty} f(t) \cdot \frac{1}{\sqrt{a}} \psi^{*}\left(\frac{t-b}{a}\right) d t\right|^{2} .
\end{aligned}
$$

Consider the family of functions obtained by shifting and scaling a "mother wavelet" $\psi$;

$$
\psi_{a, b}=\frac{1}{|a|} \psi^{*}\left(\frac{t-b}{a}\right),
$$

where $a, b \in \mathbb{R}(a \neq 0)$, and the normalization ensures that $\left\|\psi_{a, b}(t)\right\|=\|\psi(t)\|$. The wavelet should satisfy the admissibility condition:

$$
c_{\psi}=\int_{-\infty}^{\infty} \frac{|\Psi(w)|^{2}}{|w|} d w<\infty
$$

where $\Psi$ is the Fourier transform of $\psi, w$ is the frequency. In practice, $\Psi$ will always have sufficient decay so that the admissibility condition reduces to the requirement that $\Psi(0)=0$ (from discrete Fourier transform):

$$
\int_{-\infty}^{\infty} \psi(t) d t=\Psi(0)=0
$$

Because the Fourier transform is zero at the origin and the spectrum decays at high frequencies, the wavelet has bandpass behaviour. The wavelet should be normalized so that it has unit energy:

$$
\|\psi(t)\|^{2}=\int_{-\infty}^{\infty}|\psi(t)|^{2} d t=\frac{1}{2 \pi} \int_{-\infty}^{\infty}|\psi(w)|^{2} d w=1 .
$$

As a result, $\left\|\psi_{a, b}(t)\right\|^{2}=\|\psi(t)\|^{2}=1$ the continuous wavelet transform of a function $f \in L^{2}(\mathbb{R})$ is defined as:

$$
C W T_{f}(a, b)=\int_{-\infty}^{\infty} \psi_{a, b}(t) \cdot f(t) d t .
$$


Discrete wavelet transform (DWT) applies filter banks for the analysis and synthesis of a signal. Filter banks contain wavelet filters and extract the frequency content of the signal in the pre-determined subbands. The discrete wavelet transform is derived from the discretization of continuous wavelet transform by adopting the dyadic scale and translation to reduce the computational time and can be expressed by the following equation [24]:

$$
D W T_{s}(j, k)=\frac{1}{\sqrt{2^{j}}} \int_{-\infty}^{\infty} s(t) \cdot \psi^{*}\left(\frac{t-2^{j} k}{2^{j}}\right) d t,
$$

where $j$ and $k$ are integers, $2^{j}$ and $2^{j} k$ represent the scale and translation parameter respectively. The original signal $s(t)$ passes through a set of low pass and high pass filters emerging as low frequency (approximations, $a_{i}$ ) and high frequency (details, $d_{i}$ ) signals at each decomposition level $i$. They are usually finite impulse response filters whose impulse response (or response to any finite length input) is of finite duration, because it settles to zero in finite time. Therefore, the original signal $s(t)$ can be written as:

$$
s(t)=a_{n}+\sum_{i=1}^{n} d_{i} .
$$

The wavelet function $\psi$ and scaling function $\varphi$ can be defined as follows:

$$
\begin{gathered}
\psi_{j, k}[t]=2^{\frac{j}{2}} \sum_{k} d_{j, k} \psi\left[2^{j} t-k\right], \\
\phi_{j, k}[t]=2^{\frac{j}{2}} \sum_{k} c_{j, k} \phi\left[2^{j} t-k\right],
\end{gathered}
$$

where $d_{j, k}$ and $c_{j, k}$ are the wavelet and scaling coefficients at scale $j$ [38].

Assuming the signal $X[t]=\left(v_{0}, \ldots, v_{N-1}\right)$, the sampling number is $N=2^{j}$, where $j$ is an integer. For $X_{j}[t]$ at scale $j$ decomposed to the scale $j-1$ of DWT model can be defined as [39]:

$$
\begin{gathered}
\operatorname{DWT}\left(X_{j}[t]\right)= \\
=2^{\frac{j-1}{2}} \cdot\left(\sum_{k=0} c A_{j-1, k} \phi\left[2^{j-1} t-k\right]+\sum_{k=0} c D_{j-1, k} \psi\left[2^{j-1} t-k\right]\right), \\
0 \leq k \leq \frac{N}{2^{j}}-1,
\end{gathered}
$$

where

$$
\begin{gathered}
c A_{j-1, k}=\sum_{h=0}^{\frac{N}{2^{j}}-1} c_{j, h} v_{j, h+2 n}, \quad c D_{j-1, k}=\sum_{h=0}^{\frac{N}{2^{j}}-1} d_{j, h} v_{j, h+2 n}, \\
d_{h}=(-1)^{h} c_{2 p-1-h}, \quad p=N / 2^{j} .
\end{gathered}
$$

The frequency band of each wavelet level is defined by Parameswariah and Cox [40]:

$$
f=2^{j} \cdot F_{s} / N
$$

and the maximum frequency is:

$$
f_{\text {max }}=F_{s} / 2 \text {, }
$$

where $f$ is the higher frequency limit of the frequency band represented by the level $j, F_{s}$ is the sampling frequency and $N$ is the number of data points in the input signal.

\subsection{Maximum Energy to Shannon Entropy Ratio Criteria}

Fault detection procedures based on time-frequency methods usually rely on the visual observation of contour plots. It is also known that if the wavelet matches well with the shape of the signal at a specific scale and location, a large transform value is obtained. However, a low transform value is obtained if the signal and wavelet do not correlate well. To avoid defects of visual observation, a more precise way of determining the best-suited wavelet is presented here.

The combination of the energy and Shannon entropy content of the wavelet coefficients of the signal, denoted by the Energy-to-Shannon-Entropy ratio is an appropriate indicator to choose the best wavelet for diagnosis, and it can be calculated in the following form [41] and [42]:

$$
\xi(n)=E(n) / S_{\text {entropy }}(n) .
$$

The energy content of signal wavelet coefficients is given by:

$$
E(n)=\sum_{i=1}^{m}\left|C_{n, i}\right|^{2},
$$

where $m$ is the number of wavelet coefficients, $C_{n, i}$ is the $i^{\text {th }}$ wavelet coefficient of $n^{\text {th }}$ scale.

The entropy of signal wavelet coefficients is given by:

$$
S(n)=-\sum_{i=1}^{m} p_{i} \log _{2} p_{i},
$$

where $\left(p_{1}, \ldots, p_{n}\right)$ is the energy probability distribution of the wavelet coefficients, defined as:

$$
p_{i}=\left|C_{n, i}\right|^{2} / E(n) .
$$

\subsection{Fault Size Estimation}

When there is a defect in the rolling element bearing, the rolling element hits the raceway, and a transient impulse is produced. Because the impulse with short time duration is a transient excitation, the response of 
the bearing system's natural frequency would arise. Modelling the bearing vibration system as an underdamped second order mass-spring-damper dynamic mechanical system, its unit-impulse response function can be described as follows:

$$
h(t)=\frac{1}{m \omega_{d}} e^{-\left(\xi / \sqrt{\left(1-\xi^{2}\right) \omega_{d} t}\right)} \sin \left(\omega_{d} t\right),
$$

where $m$ is the mass of the bearing vibration system, $\xi$ is the damping ratio of the mechanical system and $\omega_{d}$ is the damped natural frequency of the bearing structure [43].

To determine the defect size, multiresolution analysis (MRA) is applied by filter banks, which is a design method of most of the practically relevant discrete wavelet transforms.

Usually, two or three harmonics of the characteristic defect frequency are necessary for bearing fault diagnosis. In order to diagnose the modulation effects, the width of each band $\left(F_{j}\right)$ should be three times greater than the bearing pass frequency of the inner race, and it can be calculated by [44]:

$$
F_{j} \approx F_{s} / 2^{j+1} \text {. }
$$

This implies that the final level $J_{f}$ should satisfy:

$$
J_{f} \leq \log _{2} \frac{F_{S}}{3 r F_{R}}-1,
$$

where $F_{R}$ is the frequency of the shaft, here is $30 \mathrm{~Hz}$ and $F_{S}$ is the sampling rate that is now $25.6 \mathrm{kHz}$. Practically, $J_{f}=3$ and $J_{f}=4$ values are found to be large enough for bearing vibration diagnosis [44].

In our investigation, the value of $J_{f}=3$ is proposed. In the case of No. 30205, the tapered roller bearing in the experiment BPFO is $206.18 \mathrm{~Hz}$. Down to $3^{\text {rd }}$ level, where the transient impulse is analysed for defect width measurement, wavelet band is $1.25 \mathrm{kHz}$, which is more than 3 times greater than BPFO. However, decomposition is down to the $4^{\text {th }}$ level because of deeper resolution.

The defect size on the outer race of the bearing can be estimated from the knowledge of the duration between the entry and exit events extracted from the signal after decomposition for the wavelet. The duration of the signal is estimated by wavelet decomposition using the fundamental train frequency (FTF) and average outer race inner diameter of the bearing $\left(D_{O I}\right)$. The outer race defect width $D_{O D}$ is [12]:

$$
L_{O D}=\pi \cdot \Delta t \cdot D_{O I} \cdot F T F .
$$

This method is very useful because the defect width of the bearing can be determined only from the vibration signature. Bearing defects generate transient impulses in the vibration signal when the rollers pass through the defects. The fault frequencies can be calculated by numerically: bearing pass frequency of outer race (BPFO), bearing pass frequency of inner race (BPFI), fundamental train frequency (FTF), ball spin frequency (BSF). FTF can be calculated using the Eq. 22. [5] and [7]:

$$
F T F=\frac{f_{r}}{2}\left(1-\frac{d}{D} \cos \Phi\right),
$$

where $f_{r}$ is the rotational frequency of the shaft, $\Phi$ is the contact angle, $d$ is the inner ring diameter, $D$ is the outer ring diameter. Practically, skipping phenomena could change this theoretical value.

Analysis of the de-stressing and re-stressing points of the entry and exit events from the manufacturing defect is necessary for the fault size estimation. The peaks in signal with negative and positive sign describe the position of the ball in the defect.

\section{EXPERIMENTAL SETUP}

In this study, an experimental test rig (Figs. 1 and 2.) has been constructed to measure the vibration signatures of the tapered roller bearings properly.

The shaft in the test rig is supported by two tapered roller bearings. The one under investigation is No. 30205. Four tapered roller bearings with different manufacturing defect widths on the outer race (OR1-4) were investigated in our experiments (Table 1 ). The defect on the outer race is a line (rectangular) shape-grinding defect (Fig. 3). The shaft is driven by an alternating current motor of $0.75 \mathrm{~kW}$ (made by Cemer), the frequency of $50 \mathrm{~Hz}$, and the nominal speed of $2770 \mathrm{rpm}$, which is reduced to $1800 \mathrm{rpm}$ with a variable speed drive device. A rubber V-belt between the electric engine and the shaft provides smooth running and low vibration which aid in accurate and precise measurements. Rubber bumpers are installed to reduce vibration of the electric motor to the bearing housing to minimize harmful vibrations. The arrangement provides the option of different speeds controlled by a Schneider ATV32HU22M2 variable speed drive device. In the experiment, the speed of the shaft is measured using an optical tachometer with digital display to check the speed fluctuations. Additionally, the test rig can also be used for acoustic measurements because an anechoic chamber is installed around the test bearing house with appropriate features to suppress outside noises 
and reduce echo time. Test bearing is spanned by a screw mechanism to supply the sufficient axial force to the measurements. Constant spanning force during the measurements is measured by strain gauges in a Wheatstone-bride mode on the basis of the difference in voltage measurement.

NI 9234 dynamic signal acquisition is used in the experiments with 4 channels to vibration measurements from integrated electronic piezoelectric (IEPE) and non-IEPE sensors. The NI 9234 delivers $102 \mathrm{~dB}$ of dynamic range. Input channels simultaneously digitize signals at rates up to $51.2 \mathrm{kHz}$ per channel with built-in anti-aliasing filters [45]. A PCB IMI 603C01 vibration transducer is used, which is an industrial type platinum stock piezoelectric sensor with low noise levels, the sensitivity of 100 $\mathrm{mV} / \mathrm{g}$ and frequency range of $0.27 \mathrm{kHz}$ to $10 \mathrm{kHz}$ with a top exit 2-pin connector [46]. The accelerometer is placed on the previously ground surface of the top of the bearing house with a screw mechanism perpendicular to the axis of the rotation of the shaft. A 32-bit AMD Athlon II X2 M300 2.0 GHz processor is used for data processing which is carried out in Matlab and Labview environments. For visual validation of the defect sizes on the bearing rings Garant MM1-200 video microscope is applied, which is an incremental measuring system, with a built-in image processing with a 1.3-megapixel colour camera. Furthermore, Mahr MMQ 200 with precision roundness measuring axis, motorized vertical and horizontal measuring axis is used for roundness deviation measurement to determine both width and depth of the grinding marks.

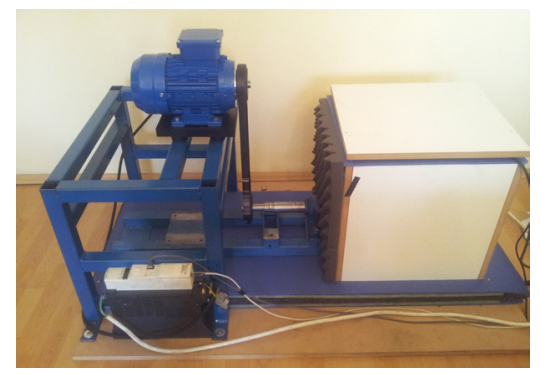

Fig. 1. Test rig for tapered roller bearing measurement

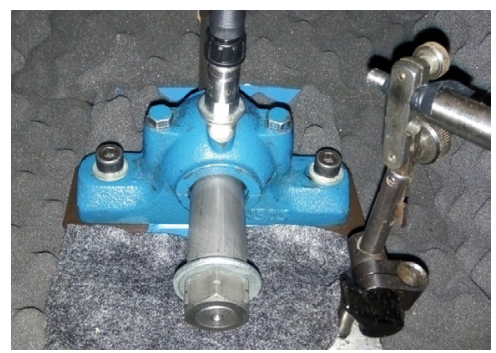

Fig. 2. Test rig for tapered roller acoustic chamber
Table 1. Geometrical parameters of grinding defects of outer rings (OR)

\begin{tabular}{ccc}
\hline Type & Width $[\mathrm{mm}]$ & Depth $[\mu \mathrm{m}]$ \\
\hline OR1 defect & 0.6311 & 6.5 \\
\hline OR2 defect & 1.2492 & 33.6 \\
\hline OR3 defect & 1.4751 & 42.3 \\
\hline OR4 defect & 1.6236 & 51.4 \\
\hline
\end{tabular}

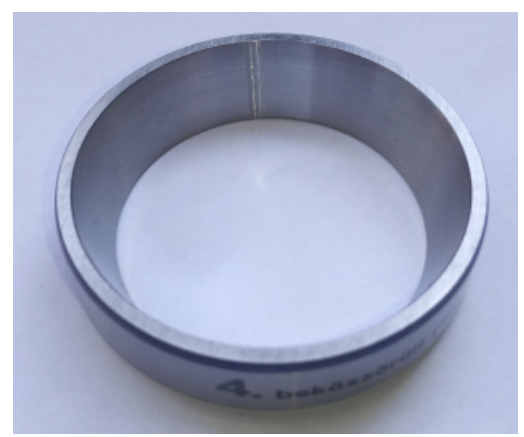

Fig. 3. Outer ring of the tapered roller bearing with grinding defect of $1.6236 \mathrm{~mm}$

\section{RESULT AND DISCUSSION}

\subsection{Optimal Wavelet Selection}

A total of nine different wavelets is considered for the present study. An appropriate base wavelet should extract the maximum amount of energy, and minimize the Shannon entropy of the corresponding wavelet coefficients. Calculated values of the energy to Shannon entropy ratios are in Tables 2 to 4 .

$\mathrm{E} / \mathrm{S}$ values are calculated from the vibration signal at the wavelet centre frequency $\left(F_{c}\right)$ of 2.09 $\mathrm{kHz}$ (Table 2).

Table 2. Calculated values of energy to Shannon entropy ratios of wavelet functions, $\mathrm{FC}=2.09 \mathrm{kHz}$

\begin{tabular}{cccccc}
\hline E/S & OR1 & OR2 & OR3 & OR4 & Mean \\
\hline Sym2 & 59.96 & 80.20 & 100.87 & 109.16 & 87.55 \\
\hline Sym5 & 65.58 & 95.37 & 117.07 & 119.92 & 99.48 \\
\hline Sym8 & 82.81 & 113.77 & 120.16 & 118.48 & 108.81 \\
\hline $\mathrm{db} 02$ & 60.91 & 81.09 & 101.12 & 113.46 & 89.14 \\
\hline $\mathrm{db} 06$ & 71.74 & 89.02 & 120.42 & 117.40 & 99.65 \\
\hline $\mathrm{db} 10$ & 77.76 & 104.69 & 120.34 & 120.45 & 105.81 \\
\hline $\mathrm{db} 14$ & 85.02 & 120.03 & 121.37 & 123.78 & 112.55 \\
\hline Meyer & 92.31 & 160.31 & 126.20 & 105.70 & 121.13 \\
\hline Morlet & 113.15 & 194.15 & 142.18 & 138.14 & 146.90 \\
\hline
\end{tabular}

After calculating the mean values of $\mathrm{E} / \mathrm{S}$ ratio values are presented in Table 2. It is observed that Morlet wavelet gives the highest value that indicates 
to be the most efficient wavelet for both fault detection and fault size estimation.

\subsection{Fault Size Estimation}

Bearing defects generate transient impulses in the vibration signal when the rollers pass through the defects.

For fault size estimation, fault frequencies are calculated which are $B P F O=206.18 \mathrm{~Hz}$, $B P F I=287.15 \mathrm{~Hz}, F T F=12.88 \mathrm{~Hz}, B S F=89.96 \mathrm{~Hz}$ in this experiment at $1800 \mathrm{rpm}$.

$$
L_{O D}=\pi \cdot \Delta t \cdot D_{O I} \cdot F T F=1713.74 \cdot \Delta t .
$$

With Eq. (24), the width of the defect can be calculated, where $D_{O I}$ is the outer ring diameter on the raceways; $\Delta t$ is the time duration between the contact points of the bearing elements. In the raw signal, entry and exit points of the groove are not identifiable because the signal at these points is weak, but wavelet decomposition makes it possible to analyse the entry and exit events. The best wavelet previously chosen by the Shannon entropy criteria gives the best method to determine the fault size from the vibration signature because it presents the best correlation with the transient impulse.

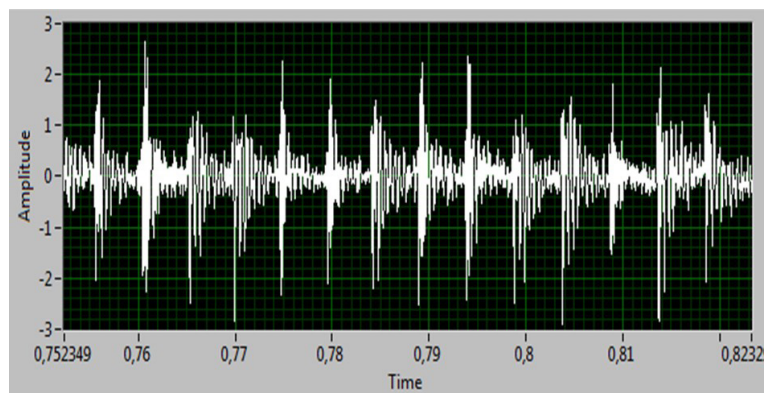

Fig. 4. Typical raw time domain signal of bearing with $0.6311 \mathrm{~mm}$ of ground fault width on the outer race

Fig. 4 presents the spectra of outer race defect of $0.6311 \mathrm{~mm}$. The highest periodic transient impulse related energy content of the burst occurs at $2.09 \mathrm{kHz}$ that causes a $5 \mathrm{~ms}$ rate of periodicity which is equal to $206.18 \mathrm{~Hz} B P F O$ frequency (Fig. 5). The spectrum was measured in all outer rings with different fault sizes, and they showed a similar manner around the peak of $2.09 \mathrm{kHz}$.

Multiresolution analysis (MRA) is made down to the $4^{\text {th }}$ level to obtain precise frequency analysis. Fig. 6 presents the wavelet decomposition tree down to the $4^{\text {th }}$ level. Higher decomposition is not necessary because it might not reveal any further information of the signal. Regarding the $B P F O$ frequency, analysis was made at $3^{\text {rd }}$ detail level $\left(c D_{3}\right)$ from $1.25 \mathrm{kHz}$ to $2.5 \mathrm{kHz}$.

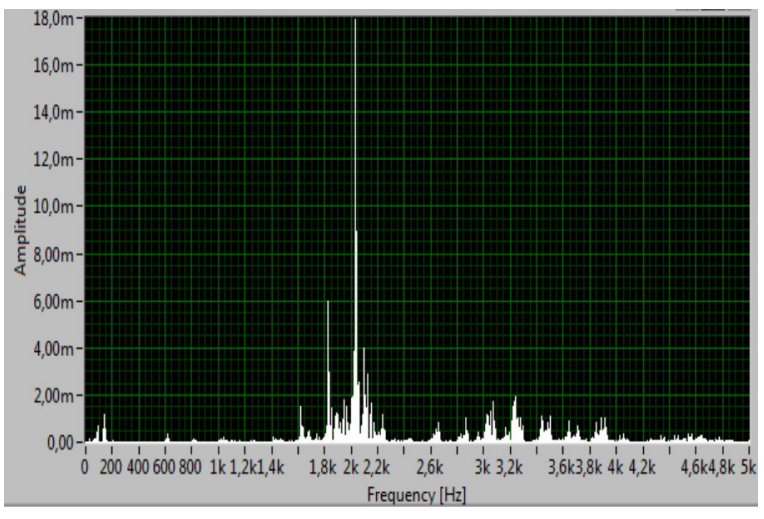

Fig. 5. Frequency domain spectrum of bearing with $0.6311 \mathrm{~mm}$ of ground fault width on the outer race, transient frequency of $2.09 \mathrm{kHz}$

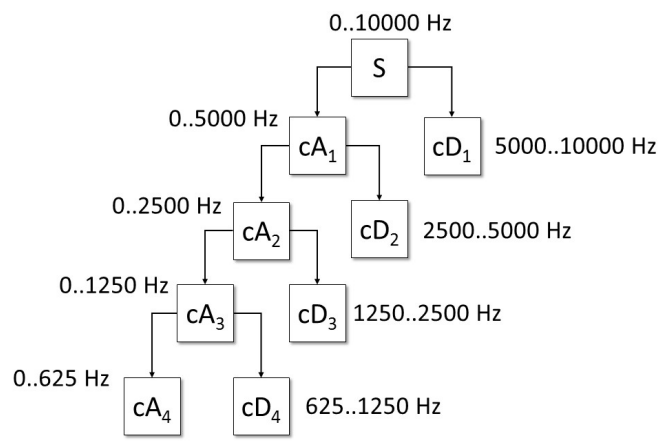

Fig. 6. Wavelet decomposition graph of the original vibration signal by MRA with frequency ranges
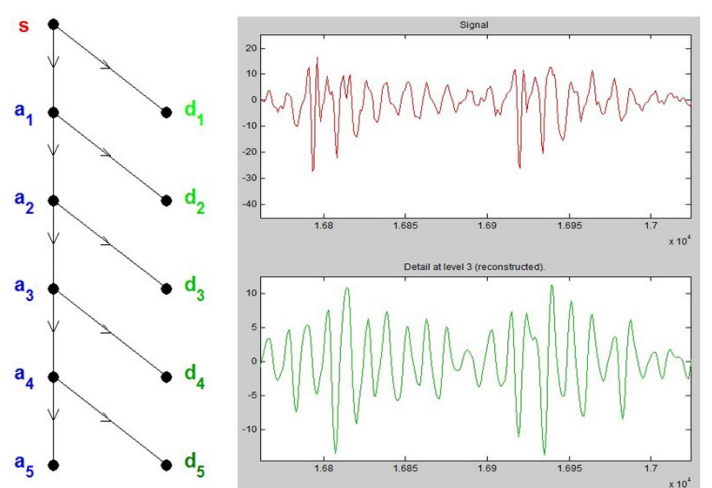

Fig. 7. Tree decomposition graph of the original vibration signal of $0.6311 \mathrm{~mm}$ fault width down to $4^{\text {th }}$ level

Fig. 7 shows the decomposition graph of the original vibration signal of $0.6311 \mathrm{~mm}$ fault width down to $4^{\text {th }}$ level. A is the entry point of the roller into the outer race defect, $\mathrm{B}$ is the maximum de-stressing, $\mathrm{C}$ is the exit point of the roller from the defect. In 
the experiment, 20 impulses were measured and the average time values of the entry, de-stressing and exit point of all four outer rings were determined for precise calculation, which yielded 240 time data points.

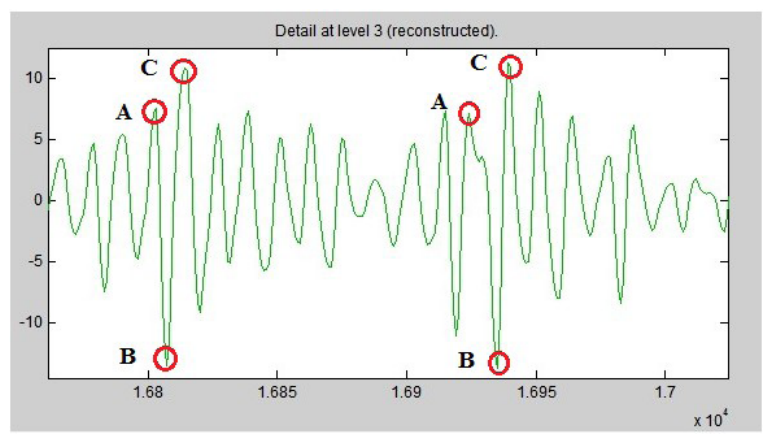

Fig. 8. Detail graph of the MRA of the original vibration signal of $0.6311 \mathrm{~mm}$ fault width at detail 3 rd level with two transient impulses, entry point (A), de-stressing point (B) and exit point (C) are highlighted in red

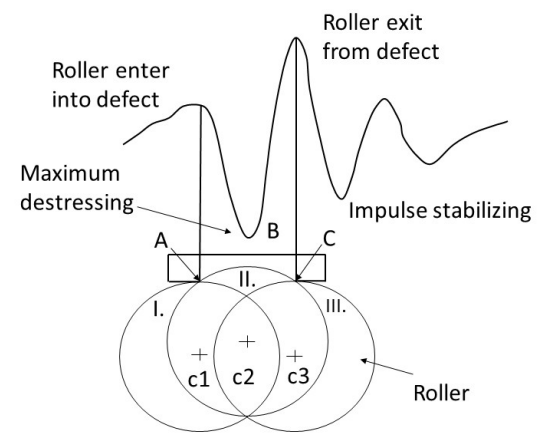

Fig. 9. Analysis of the transient impulse presenting the entry and exit points of the roller into the grinding defects on the outer ring

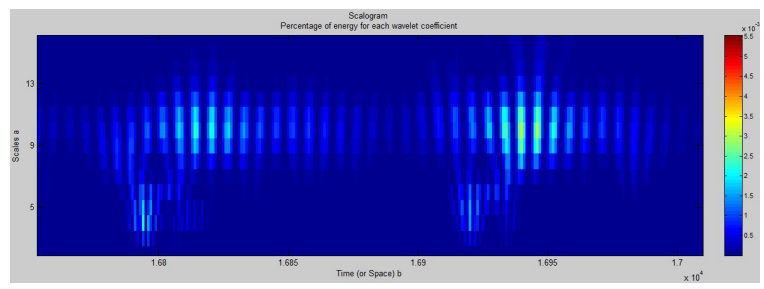

Fig. 10. Scalogram of the Morlet wavelet of the outer ring with $0.6311 \mathrm{~mm}$ fault width

Figs. 8 to 10 show the analysis of the entry point, the exit point and the de-stressing point of the roller for the purpose of fault size calculation. At point A, the roller strikes the groove base with a high impact which results in re-stressing and high impulse in the signal. After this event, the roller remains in contact with the groove base for some time and during this period impulses due to the rough surface of the groove are observed.
When the roller comes in contact with point B, it again generates high amplitude in the signal, and beyond this (i.e. after B) progressive decreases in the amplitude of the signal are observed due to elastic damping of bearing element. The roller may spin or slide during the operation of the bearing. Change in signal takes place when it slides. Furthermore, varying clearance between cage and roller changes the signal when the roller enters and exits the groove defect.

There is variation in data points for each roller crossing over the defect. Average data points for 16 successive bursts are calculated for estimating the time taken by roller to pass over the groove defect. The average of data points so calculated is converted into the time duration to cross over from A to B, considering the sampling frequency. Further using Eq. (24), the defect width was calculated in the case of all outer rings. A scalogram was applied in addition to the multiresolution analysis as was presented in Fig. 10.

\section{VERIFICATION OF THE MEASUREMENT BY IMAGE PROCESSING}

To verify the precision of the previous measurements, image processing is applied to reveal the exact geometrical size of the ground defect on the outer race. A Garant MM1-200 video microscope is used to analyse and measure the grinding marks on the rings and Mahr MMQ 200 contact equipment is applied for roundness deviation measurement of the outer rings to determine the depth of the grinding marks on the rings as Figs. 11 to 16 present.

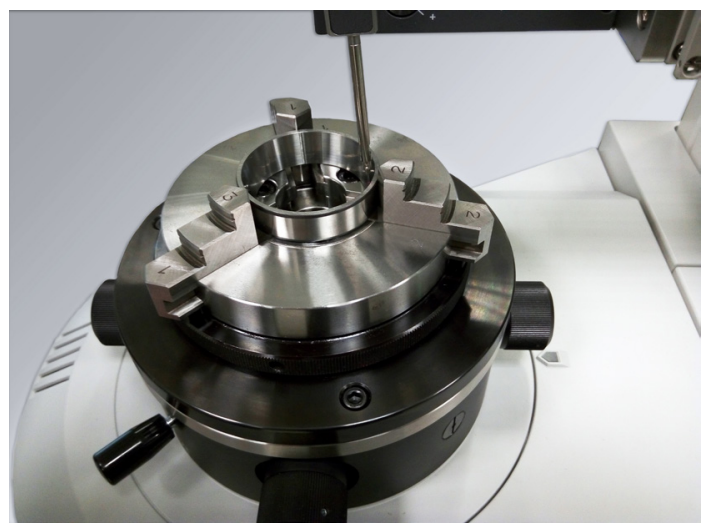

Fig. 11. Contact measurement of the outer race defect geometrical size with Mahr MMQ 200 equipment

To find the edges of the grinding marks on the outer race made by the Garant MM1-200 video microscope, Prewitt and Sobel edge detection algorithms are used as image processing technique. In 
our investigations, the Prewitt algorithm is found to be more efficient.

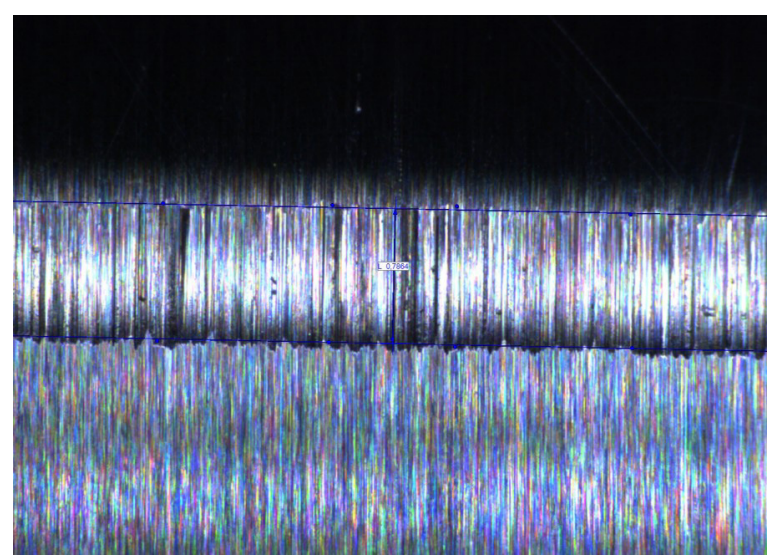

Fig. 12. Image of the optical measurement of the outer race defect width with Garant MM1-200 video microscope

The maximum difference in result has been obtained to be $4.12 \%$ for a defect width of 0.6311 $\mathrm{mm}$ by $\mathrm{db} 02$ wavelet. The width calculation and the deviation from the visually measured data using the worst wavelet for fault detection (db02), the traditionally widely used Symlet-5, and the best Morlet wavelet are found in Tables 3 to 5. The Morlet wavelet

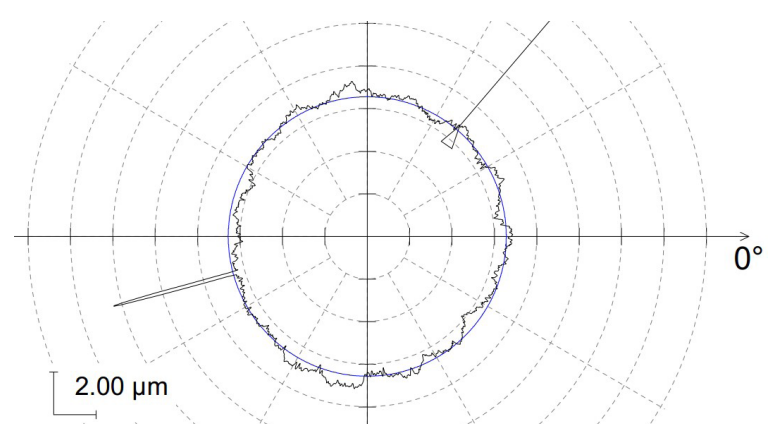

Fig. 13. Result of the roundness measurement of the outer race defect with Mahr MMQ 200 equipment, OR1 defect

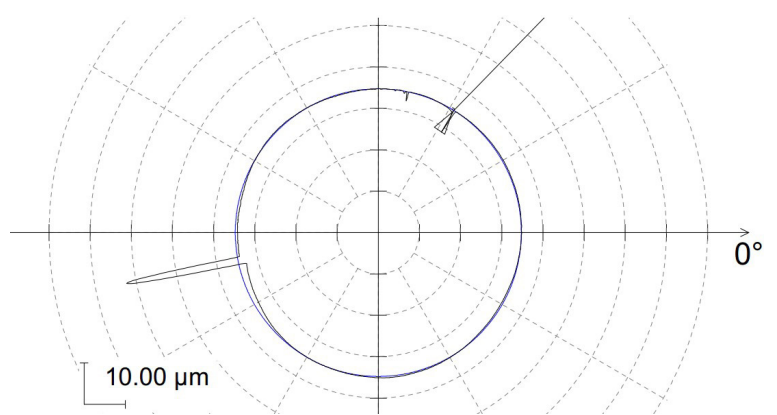

Fig. 14. Result of the roundness measurement of the outer race defect with Mahr MMQ 200 equipment, OR2 defect provides the most accurate width measurement from the vibration signal.

Table 3. Deviation values of geometrical width of the fault from the vibration signal and optically measured values with db02 wavelet

\begin{tabular}{lcccc}
\hline & $\begin{array}{c}\text { OR1 } \\
\text { defect }\end{array}$ & $\begin{array}{c}\text { OR2 } \\
\text { defect }\end{array}$ & $\begin{array}{c}\text { OR3 } \\
\text { defect }\end{array}$ & $\begin{array}{c}\text { OR4 } \\
\text { defect }\end{array}$ \\
\hline $\begin{array}{l}\text { Calculated defects width } \\
\text { [mm] }\end{array}$ & 0.657 & 1.521 & 1.277 & 1.653 \\
\hline $\begin{array}{l}\text { Optically measured defect } \\
\text { width [mm] }\end{array}$ & 0.6311 & 1.4751 & 1.2492 & 1.6236 \\
\hline $\begin{array}{l}\text { Deviation between calculated } \\
\text { and measured data [\%] }\end{array}$ & 4.12 & 3.11 & 2.24 & 1.78 \\
\hline Mean deviation [\%] & \multicolumn{4}{c}{2.81} \\
\hline
\end{tabular}

Table 4. Deviation values of geometrical width of the fault from the vibration signal and optically measured values with Symlet-5 wavelet

\begin{tabular}{lcccc}
\hline & $\begin{array}{c}\text { OR1 } \\
\text { defect }\end{array}$ & $\begin{array}{c}\text { OR2 } \\
\text { defect }\end{array}$ & $\begin{array}{c}\text { OR3 } \\
\text { defect }\end{array}$ & $\begin{array}{c}\text { OR4 } \\
\text { defect }\end{array}$ \\
\hline $\begin{array}{l}\text { Calculated defects width } \\
\text { [mm] }\end{array}$ & 0.646 & 1.4481 & 1.269 & 1.639 \\
\hline $\begin{array}{l}\text { Optically measured defect } \\
\text { width [mm] }\end{array}$ & 0.6311 & 1.4751 & 1.2492 & 1.6236 \\
\hline $\begin{array}{l}\text { Deviation between calculated } \\
\text { and measured data [\%] }\end{array}$ & 2.41 & 1.83 & 1.56 & 0.92 \\
\hline Mean deviation [\%] & \multicolumn{4}{c}{1.68} \\
\hline
\end{tabular}

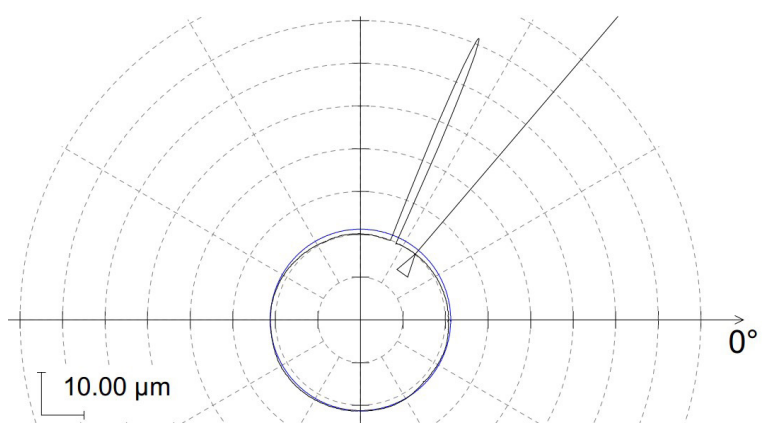

Fig. 15. Result of the roundness measurement of the outer race defect with Mahr MMQ 200 equipment, OR3 defect

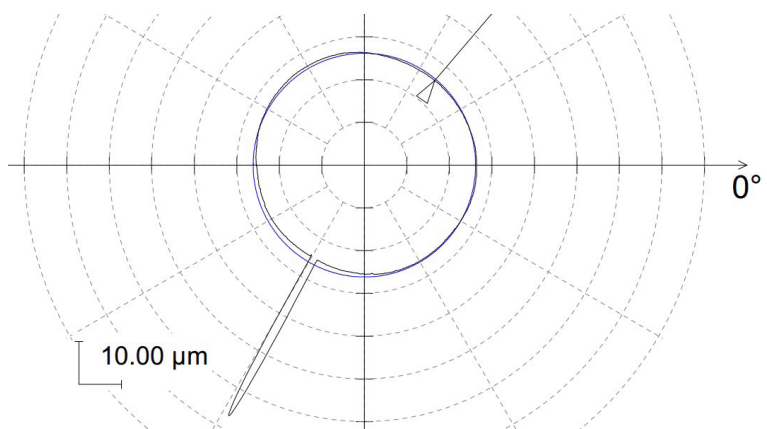

Fig. 16. Result of the roundness measurement of the outer race defect with Mahr MMQ 200 equipment, OR4 defect 
Table 5. Deviation values of geometrical width of the fault from the vibration signal and optically measured values with Morlet wavelet

\begin{tabular}{lcccc}
\hline & $\begin{array}{c}\text { OR1 } \\
\text { defect }\end{array}$ & $\begin{array}{c}\text { OR2 } \\
\text { defect }\end{array}$ & $\begin{array}{c}\text { OR3 } \\
\text { defect }\end{array}$ & $\begin{array}{c}\text { OR4 } \\
\text { defect }\end{array}$ \\
\hline $\begin{array}{l}\text { Calculated defects width } \\
\text { [mm] }\end{array}$ & 0.644 & 1.502 & 1.266 & 1.637 \\
\hline $\begin{array}{l}\text { Optically measured defect } \\
\text { width [mm] }\end{array}$ & 0.6311 & 1.4751 & 1.2492 & 1.6236 \\
\hline $\begin{array}{l}\text { Deviation between calculated } \\
\text { and measured data [\%] }\end{array}$ & 2.06 & 1.69 & 1.38 & 0.84 \\
\hline Mean deviation [\%] & \multicolumn{4}{c}{1.49} \\
\hline
\end{tabular}

\section{CONCLUSIONS}

A technique based on wavelet transform using nine different real-valued wavelets has been proposed for measuring the outer race manufacturing defect widths of tapered roller bearings.

Wavelet coefficients were determined at constant scale value of the scalograms of four outer rings with grinding manufacturing defects. Then, wavelet coefficients at the highest local maxima of the scalograms were calculated. Moreover, Butterworth filter was applied near the fault generated transient impulse with the frequency of $2.09 \mathrm{kHz}$ to suppress noise related frequency components and enhance the useful information from the vibration signature. Nine real-valued wavelets were analysed, and it was determined that Morlet wavelet was the best for the manufacturing fault detection in all cases on the basis of the Shannon Entropy Criteria. Furthermore, the width measurement of the outer ring grinding fault was executed with all nine wavelets. The best wavelet previously chosen by Shannon Entropy Criteria creates the opportunity to determine the manufacturing defect width in the most accurate way because it presents the best correlation with the transients. The proposed technique has been successfully implemented for measuring defect width over a range of $0.6311 \mathrm{~mm}$ to $1.6236 \mathrm{~mm}$. The defect width has also been verified by an optical microscope and contact roundness measurement device using image processing techniques. The maximum deviation of the two values of defect width obtained using the aforementioned two different visual measurement validation approaches is $4.12 \%$ for a defect width of $0.6311 \mathrm{~mm}$.

\section{REFERENCES}

[1] Patel, V.N., Tandon, N., Pandey, R.K. (2012). Defect detection in deep groove ball bearing in the presence of external vibration using envelope analysis and Duffing oscillator.
Measurement, vol. 45, no. 5, p. 960-970, D0l:10.1016/j. measurement.2012.01.047.

[2] Khanam, S., Tandon, N., Dutt, J.K. (2012). Fault identification of rolling element bearings from vibration signals: An application of Kalman and $\mathrm{H}_{\infty}$ filters. 10th International Conference on Vibrations in Rotating Machinery, p. 703-713, DOI:10.1533/9780857094537.11.703.

[3] Al-Ghamd, A.M., Mba, D. (2006). A comparative experimental study on the use of acoustic emission and vibration analysis for bearing defect identification and estimation of defect size. Mechanical Systems and Signal Processing, vol. 20, no. 7, p. 1537-1571, D0I:10.1016/j.ymssp.2004.10.013.

[4] Elforjani, M., Mba, D. (2010). Accelerated natural fault diagnosis in slow speed bearings with acoustic emission. Engineering Fracture Mechanics, vol. 77, no. 1, p. 112-127, D0I:10.1016/j.engfracmech.2009.09.016.

[5] Sawalhi, N., Randall, R.B. (2011). Vibration response of spalled rolling element bearings: Observations, simulations and signal processing techniques to track the spall size. Mechanical Systems and Signal Processing, vol. 25, no. 3, p. 846-870, DOI:10.1016/j.ymssp.2010.09.009.

[6] Peng, Z.K., Chu, F.L. (2004). Application of the wavelet transform in machine condition monitoring and fault diagnostics. Mechanical Systems and Signal Processing, vol. 18, no. 2, p. 199-221, DOI:10.1016/S0888-3270(03)00075-X.

[7] Prabhakar, S., Mohanty, A.R., Sekhar, A.S. (2002). Application of discrete wavelet transform for detection of ball bearing race faults. Tribology International, vol. 35, no. 12, p. 793-800, D0I:10.1016/S0301-679X(02)00063-4.

[8] Shi, D.F., Wang, W.J., Qu, L.S. (2004). Defect detection for bearings using envelope spectra of wavelet transform. ASME Journal of Vibration and Acoustics, vol. 126, no. 4, p. 567357, DOI:10.1115/1.1804995.

[9] Nikolaou, N.G., Antoniadis, I.A. (2002). Demodulation of vibration signals generated by defects in rolling element bearings using complex shifted morlet wavelets. Mechanical Systems and Signal Processing, vol. 16, no. 4, p. 677-694, DOl:10.1006/mssp.2001.1459.

[10] Qiu, H., Lee, J., Lin, J., Yu, G. (2006). Wavelet filter-based weak signature detection method and its application on rolling element bearing prognostics. Journal of Sound and Vibration, vol. 289, no. 4-5, p. 1066-1090, D0l:10.1016/j. jsv.2005.03.007.

[11] Junsheng, C., Dejie, Y., Yu, Y. (2007). Application of an impulse response wavelet to fault diagnosis of rolling bearings. Mechanical Systems and Signal Processing, vol. 21, no. 2, p. 920-929, D0I:10.1016/j.ymssp.2005.09.014.

[12] Kumar, R., Singh, M. (2013). Outer race defect width measurement in tapered roller bearing using discrete wavelet transform of vibration signal. Measurement, vol. 46, no. 1, p. 537-545, DOI:10.1016/j.measurement.2012.08.012.

[13] Awal, M. A., Mostafa, S. S., Ahmad, M. (2012). Quality assessement of ECG signal using symlet wavelet transform. Proceedings of International Conference on Advances in Electrical Engineering, p. 129-134.

[14] Chavan, M. S., Mastorakis, N., Chavan, M. N., Gaikwad, M. S. (2012). Implementation of SYMLET Wavelets to Removal of Gaussian Additive Noise from Speech Signal. 
Recent Researches in Communications, Automation, Signal Processing, Nanotechnology, Astronomy and Nuclear Physics, p. 37-41.

[15] Kumar, R., Jena, D.P., Bains, M. (2010). Identification of inner race defect in radial ball bearing using acoustic emission and wavelet analysis. Proceedings of ISMA 2010 including USD 2010 Leuven, p. 2883-2891.

[16] Yan, R., Gao, R.X. (2009). Multi-scale enveloping spectrogram for vibration analysis in bearing defect diagnosis. Tribology International, vol. 42, no. 2, p. 293-302, D0l:10.1016/j. triboint.2008.06.013.

[17] Patil, M.S., Mathew, J., Rajendrakumar, P.K., Desai, S. (2010). A theoretical model to predict the effect of localized defect on vibrations associated with ball bearing. International Journal of Mechanical Sciences, vol. 52, no. 9, p. 1193-1201, D0I:10.1016/j.ijmecsci.2010.05.005.

[18] He, W., Jiang, Z., Feng, K. (2009). Bearing fault detection based on optimal wavelet filter and sparse code shrinkage. Measurement, vol. 42, no. 7, p. 1092-1102, D0l:10.1016/j. measurement.2009.04.001.

[19] Sawalhi, N., Randall, R.B. (2011). Vibration response of spalled rolling element bearings: observations, simulations and signal processing techniques to track the spall size. Mechanical Systems and Signal Processing, vol. 25, no. 3, p. 846-870, D0l:10.1016/j.ymssp.2010.09.009.

[20] Kumar, R., Singh, M. (2013). Outer race defect width measurement in tapered roller bearing using discrete wavelet transform of vibration signal. Measurement, vol. 46, no. 1, p. 537-545, D0I:10.1016/j.measurement.2012.08.012.

[21] Khanam, S., Tandon, N., Dutt, J.K. (2014). Fault size estimation in the outer race of ball bearing using discrete wavelet transform of the vibration signal. Procedia Technology, $2^{\text {nd }}$ International Conference on Innovations in Automation and Mechatronics Engineering, vol. 14, p. 12-19, D0l:10.1016/j. protcy.2014.08.003.

[22] Tóth, L., Tóth, T. (2013). Construction of a realistic signal model of transients for a ball bearing with inner race fault. Acta Polytechnica Hungarica, vol. 10, no. 1, p. 63-80.

[23] Tóth, L., Tóth T. (2013). On finding wavelet basis for bearing fault detection. Acta Polytechnica Hungarica, vol. 10, no. 3, p. 17-35.

[24] Salguerio, J., Persin, G., Vizintin, J., Ivanovic, M., Dolenc, B. (2013). On-line oil monitoring and diagnosis. Strojniški vestnik - Journal of Mechanical Engineering, vol. 59, no. 10, p. 604612, D0I:10.5545/sv-jme.2013.973.

[25] Li, Z., Ma, Z., Liu, Y., Teng, W., Jiang, R. (2015). Crack fault detection for a gearbox using discrete wavelet transform and an addaptive resonance theory neural network. Strojniški vestnik - Journal of Mechanical Engineering, vol. 61, no. 1, p. 63-73, D0I:10.5545/sv-jme.2014.1769.

[26] Mankovits, T., Szabó, T., Kocsis, I., Páczelt, I. (2014). Optimization of the Shape of Axi-Symmetric Rubber Bumpers. Strojniški vestnik - Journal of Mechanical Engineering, vol. 60, no. 1, p. 61-71, D0I:10.5545/sv-jme.2013.1315.

[27] Khanam, S., Tandon, N., Dutt, J.K. (2016). Multi-event excitation force model for inner race defect in a rolling element bearing. Journal of Tribology, vol. 138, no. 1, art. No. 011106 , DOI:10.1115/1.4031394.
[28] Borghesani, P., Pennacchi, P., Randall, R.B., Sawalhi, N., Ricci, R. (2013). Application of cepstrum pre-whitening for the diagnosis of bearing faults under variable speed conditions. Mechanical Systems and Signal Processing, vol. 36, no. 2, p. 370-384, D0I:10.1016/J.ymssp.2012.11.001.

[29] Figlus, T., Stanczyk, M. (2016). A method for detecting damage to rolling bearings in toothed gears of processing lines. Metalurgija, vol. 55 no. 1, p. 75-78.

[30] Tabaszewski, M. (2014). Optimization of a nearest neighbors classifier for diagnosis of condition of rolling bearings. Diagnostyka, vol. 15, no. 1, p. 37-42.

[31] Gligorijevic, J., Gajic, D., Brkovic, A., Savic-Gajic, I., Georgieva, O., Di Gennaro, S. (2016). Online condition monitoring of bearings to support total productive maintenance in the packaging materials industry. Sensors, vol. 16 no. 3, p. 316, DOI:10.3390/s16030316.

[32] Strączkiewicz, M., Czop, P., Barszcz, T. (2016). Supervised and unsupervised learning process in damage classification of rolling element bearings. Diagnostyka, vol. 17, no. 2, p. 71-80.

[33] Slavič, J., Brković, A., Boltežar, M. (2011). Typical bearing-fault rating using force measurements: application to real data. Journal of Vibration and Control, vol. 17, no 14, p. 2164-2174, DOl:10.1177/1077546311399949.

[34] Abboud, D., Antoni, J., Eltabach, M., Sieg-Zieba, S. (2015). Angle time cyclostationarity for the analysis of rolling element bearing vibrations. Measurement, vol. 75, p. 29-39, D0I:10.1016/j.measurement.2015.07.017.

[35] Paya, B.A., Esat, I.I., Badi, M.N.M. (1997). Artificial neural network based fault diagnostics of rotating machinery using wavelet transforms as a preprocessor. Mechanical Systems and Signal Processing, vol. 11, no. 5, p. 751-765, D0l:10.1006/mssp.1997.0090.

[36] Antoni, J. (2007). Cyclic spectral analysis of rolling-element bearing signals: Facts and fictions. Journal of Sound and Vibration, vol. 304, no. 3-5, p. 497-529, Dol:10.1016/j. jsv.2007.02.029.

[37] Misiti, M., Misiti, Y., Oppenheim, G., Poggi, J.-M. (eds.) (2007). Wavelets and their Applications. ISTE, London, DOI:10.1002/9780470612491.

[38] Wu, J.D., Liu, C.H. (2008). Investigation of engine fault diagnosis using discrete wavelet transform and neural network. Expert Systems with Applications, vol. 35, no. 3, p. 1200-1213, D0I:10.1016/J.eswa.2007.08.021.

[39] Teng, W., Wang, F., Zhang, K., Liu, Y., Ding, X. (2014). Pitting fault detection of a wind turbine gearbox using empirical mode decomposition. Strojniški vestnik - Journal of Mechanical Engineering, vol. 60, no. 1, p. 12-20, D0l:10.5545/svjme.2013.1295.

[40] Parameswariah, C., Cox, M. (2002). Frequency characteristics of wavelets. IEEE Transactions on Power Delivery, vol. 17, no. 3, p. 800-804, D0I:10.1109/TPWRD.2002.1022806.

[41] Kankar, P.K., Sharma, S.C., Harsha, S.P. (2011). Fault diagnosis of ball bearings using continuous wavelet transform. Applied Soft Computing, vol. 11, no. 2, p. 2300-2312, DOl:10.1016/j.asoc.2010.08.011.

[42] Kankar, P.K., Sharma, S.C., Harsha, S.P. (2013). Fault diagnosis of rolling element bearing using cyclic autocorrelation and 
wavelet transform. Neurocomputing, vol. 110, p. 9-17, D0I:10.1016/j.neucom.2012.11.012.

[43] Feng, K., Jiang, Z., He, W., Qin, Q. (2011). Rolling element bearing fault detection based on optimal antisymmetric real Laplace wavelet. Measurement, vol. 44, no. 9, p. 1582-1591, D0l:10.1016/j.measurement.2011.06.011.

[44] Nikolaou, N.G., Antoniadis, I.A. (2002). Rolling element bearing fault diagnosis using wavelet packets. NDT \& $E$
International, vol. 35, no. 3, p. 197-205, Dol:10.1016/S09638695(01)00044-5.

[45] NI 9234 datasheet: from http://www.ni.com/datasheet/pdf/ en/ds-316, accessed on 2016-02-04.

[46] PCB IMI 603C01 transducer, from https://www.pcb. com/contentstore/docs/PCB_Corporate/IMI/Products/ Manuals/603C01.pdf, accessed on 2016-02-04. 